\title{
Increased incidence of hypotension in elderly patients who underwent emergency airway management: an analysis of a multi-centre prospective observational study
}

Kohei Hasegawa ${ }^{1 *}$, Yusuke Hagiwara², Taichi Imamura ${ }^{3}$, Takuyo Chiba ${ }^{4}$, Hiroko Watase ${ }^{5}$, Calvin A Brown 3rd ${ }^{6}$ and David FM Brown ${ }^{7}$

\begin{abstract}
Background: Although the number of elderly increases disproportionately throughout the industrialised nations and intubation-related cardiovascular compromise is associated with hospital mortality, no emergency medicine literature has reported the direction and magnitude of effect of advanced age on post-intubation hypotension. We seek to determine whether advanced age is associated with an increased rate of hypotension at airway management in emergency departments (EDs).

Methods: We conducted an analysis of a multi-centre prospective observational study of 13 Japanese EDs from April 2010 to March 2012. Inclusion criteria were all adult non-cardiac-arrest patients who underwent emergency intubation. We excluded patients in whom airway management was performed for shock or status asthmaticus as the principal indication. Patients were divided into two groups defined a priori: age $\geq 65$ years old (elderly group) and age $<65$ years old (younger group). The primary outcome measure was post-intubation hypotension in the ED. Results: During the 24-month period, 4,043 subjects required emergency airway management at $13 \mathrm{EDs}$. Among these, the database recorded 3,872 intubations (capture rate 96\%). Of 1,903 eligible patients, 975 patients were age $\geq 65$ years (51\%) and 928 patients were age $<65$ years (49\%). The elderly group had a significantly higher rate of post-intubation hypotension compared with the younger group [3\% vs. 1\%; unadjusted OR 2.7 (95\% Cl, 1.3-5.6); $P=0.005]$. In a model controlling for potential confounders (sex, principal indication, method, medication used to intubate, multiple intubation attempts), advanced age had an adjusted OR for post-intubation hypotension of 2.6 $(95 \% \mathrm{Cl}, 1.3-5.6 ; P=0.01)$.

Conclusions: In this large multi-centre study of ED patients who underwent emergent airway management, we found that elderly patients have a significantly higher risk of post-intubation hypotension. These data provide implications for the education and practice of ED airway management that may lead to better clinical outcomes and improved patient safety.
\end{abstract}

Keywords: Airway management, Emergency department, Elderly, Hypotension, Adverse events

\footnotetext{
* Correspondence: khasegawa1@partners.org

'Departments of Emergency Medicine, Massachusetts General Hospital, 326

Cambridge Street, Suite 410, Boston, MA 02114, USA

Full list of author information is available at the end of the article
} 


\section{Background}

People aged 65 and older represent approximately 13\% of the US population, 40 million in 2010 [1]. US Census data estimate that approximately $20 \%$ of Americans will be over age 65 by the year 2030 [2]. Similar trends are apparent throughout the developed world [3]. The disproportionate increase in the number of elderly has been accompanied by an increase in the use of health care, including the emergency department (ED), by patients with comorbid conditions, such as congestive heart failure and coronary artery disease [4].

Many elderly patients with comorbid disease require ED airway management during the course of their illness. In addition to the effect of comorbidities, aging itself brings a number of physiologic changes, such as diminished cardiovascular reserve [5]. Previous studies highlighted that cardiovascular compromise such as post-intubation hypotension in the ED setting is associated with organ dysfunction, prolonged intensive care stay and hospital mortality [6-8]. Although there are several reports that medications used for induction cause more pronounced cardiovascular compromise in elderly patients than in younger patients, most of them are perioperative studies within single institutions [9-13]. Despite its clinical relevance, no emergency medicine literature has reported the direction and magnitude of effect of advanced age on intubation-related cardiovascular events.

Using a robust multi-centre registry of emergency airway management, we aimed to determine whether patients aged 65 years or older have a higher incidence of post-intubation hypotension in the ED.

\section{Methods}

\section{Study design and setting}

This study was an analysis of the Japanese Emergency Airway Network (JEAN) Registry, a prospective observational multi-centre data registry, with all data collection planned a priori. The study setting, methods of measurement and measured variables have been reported previously $[14,15]$. In summary, JEAN was a consortium of 13 academic and community medical centres from different geographic regions across Japan. All 13 EDs were staffed by emergency attending physicians, and 12 had affiliations with emergency medicine residency training programs. The participating institutions were certified as level I $(n=10)$ or level II equivalent $(n=3)$ trauma centres. They had a median ED census of 30,000 patient visits per year (range, 9,000 to 67,000). The study was approved by the Institutional Review Board of each participating centre with waiver of informed consent prior to data collection and performed in accordance with the Helsinki Declaration.

\section{Selection of participants}

All adult patients aged 18 years or older who underwent emergency tracheal intubation at a participating ED during a 24-month period (April 2010 to March 2012) were included in the study. We excluded those patients in whom airway management was performed for cardiac arrest, shock (systolic blood pressure $<90 \mathrm{mmHg}$ ) or status asthmaticus as the principal indication.

\section{Data collection}

Case ascertainment was passive, relying on self-reporting by intubators on duty in the ED. After each intubation, the intubator completed a standardised form that included the patient's age, sex, indication for intubation, methods of intubation, devices and all medications used to facilitate intubation, operator level of training and specialty, number of attempts, success or failure, and intubation-related adverse events. We monitored compliance continuously by reviewing professional billing codes, cross-referencing our findings with the intubation data forms. When a patient underwent an intubation but for whom we had received no data collection form, the intubator was interviewed by one of the investigators to fill out the data.

\section{Outcome measures}

During the development phase, key definitions were agreed on. "Adverse events" were a priori defined as intubation-associated events with two categories: hypotension and other adverse events. Hypotension was defined as any recorded systolic blood pressure $<90 \mathrm{mmHg}$ after airway management in EDs [16]. Other adverse events included dysrhythmia, cardiac arrest, death, oesophageal intubation with delayed recognition, dental or lip trauma, mainstem bronchial intubation, regurgitation, hypoxemia and airway trauma. Cardiac arrest includes asystole, bradycardia or dysrhythmia with non-measurable blood pressure and cardiopulmonary resuscitation during or after intubation. Oesophageal intubation was defined as misplacement of the tracheal tube in the upper oesophagus or hypopharynx with a lapse of time and clinical deterioration, such as hypoxemia, before the removal of the misplaced tube [16-18]. Regurgitation was defined as gastric contents that required suction removal during laryngoscopy in a previously clear airway. Hypoxemia was defined as pulse oximetry saturation $<90 \%$.

An intubation "attempt" was defined as a single insertion of the laryngoscope (or other device) past the teeth. An attempt was successful if it resulted in a tracheal tube being placed through the vocal cords with confirmation by a quantitative or colorimetric end-tidal carbon dioxide monitor [16]. Multiple intubation attempts were defined as three or more intubation attempts [19]. 


\section{Statistical analysis}

We analysed the compiled data with simple descriptive statistics. Continuous data are presented as means and standard deviations (SD) or medians and interquartile ranges (IQRs) as appropriate based on distribution of the data; categorical data are reported as proportions and $95 \%$ confidence intervals (CIs). For the purposes of this analysis, the cohort was divided into two groups defined a priori based on the patient's age: patients aged 65 years or older (elderly group) and patients aged less than 65 years (younger group). These classifications were defined in a written protocol prior to querying the database or analysing any data.

The primary outcome measure was a post-intubation hypotension. The occurrence of the primary outcome was compared between the groups using the chi-square test for the difference in proportions. The secondary outcome measure was the occurrence of any adverse event. Odds ratios (OR) were calculated to determine independent predictors of adverse events. Given the dichotomous outcome, we performed multivariable logistic regression modelling, adjusting for important patient and ED factors that have been shown to predict adverse events [16,19-23]. These factors included sex, principal indication for intubation, initial method of intubation, sedatives and multiple intubation attempts. In the regression model, the predictive effects on the rate of adverse events were assessed for age $\geq 65$ years. This elderly group was coded as a contrast variable against age $<65$ years. We tested for effect modification between rapid sequence intubation and sedatives by including their interaction terms in a model with adverse event as the outcome (data not shown). Results did not indicate effect modification and so interaction terms were not included in the final model. The discrimination and calibration of the model was determined by using the c-statistic and Hosmer-Lemeshow test, respectively.

In the sensitivity analyses, we repeated the multivariable analysis, comparing patients aged 80 years or older versus patients aged less than 80 years. We also conducted an analysis modelling the age as an ordinal variable. All ORs are presented with 95\% CIs. All $P$ values are two-sided, with a $P$ value of less than 0.05 considered statistically significant. Data analyses were conducted with SAS statistical software (version 9.3; SAS Institute, Cary, NC).

\section{Results}

\section{Characteristics of study subjects}

During the 24-month period, there were 4,043 subjects requiring emergency airway management at 13 EDs (Figure 1). Among these, the database recorded 3,872 intubations (capture rate 96\%). We excluded 1,866 patients who underwent airway management for cardiac arrest, shock or status asthmaticus and 103 patients who were aged younger than 18 years. The remaining 1,903 patients were analysed in the study.

Baseline characteristics for two groups appear in Table 1 . The overall median age was 65 years; $51 \%$ were 65 years or older $(n=975)$. Most intubation involved medical emergencies. ED airway management choices are displayed in Table 2. Sedatives, without neuromuscular

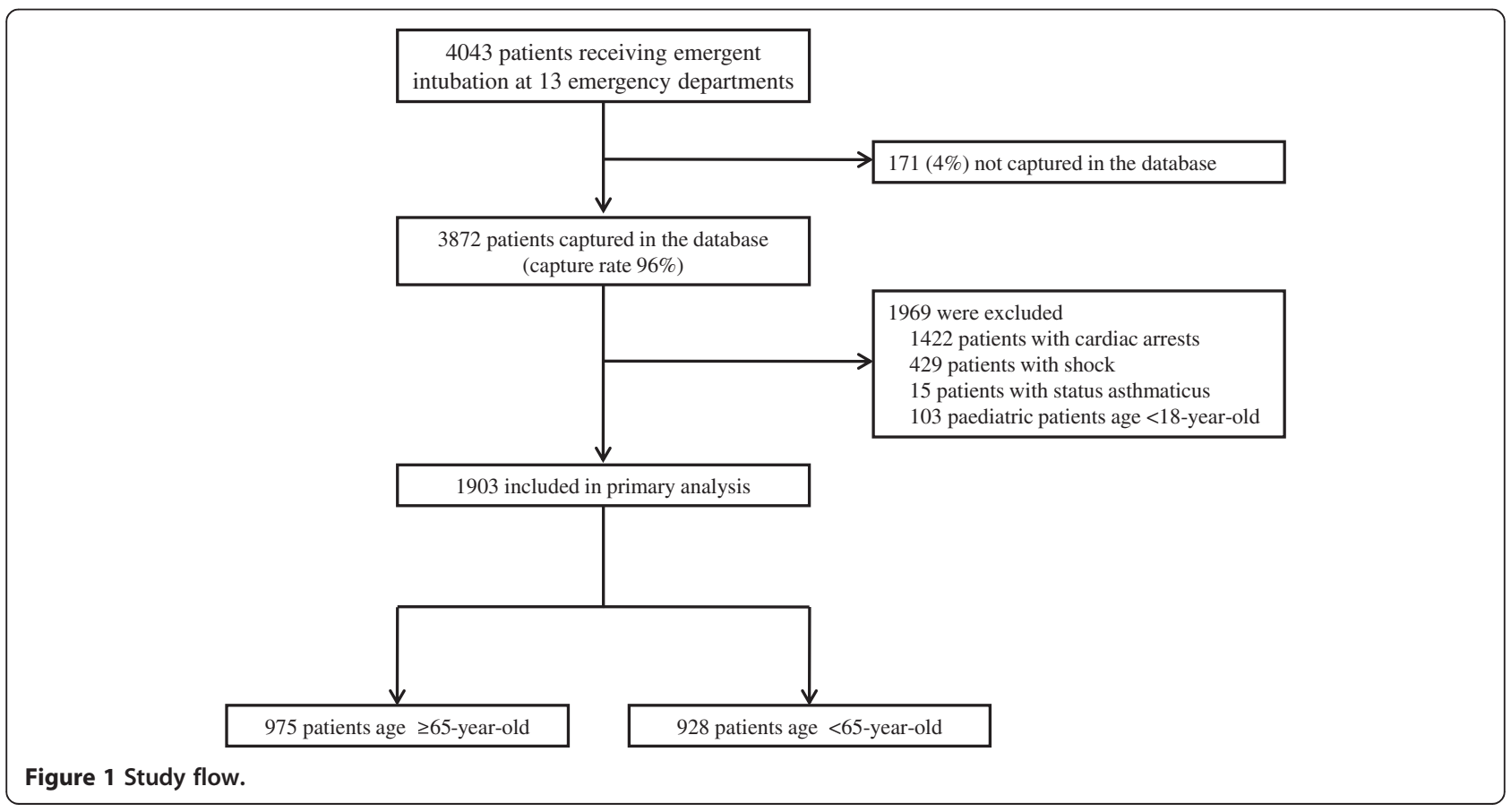


Table 1 Baseline characteristics of 1,903 patients who underwent emergent airway management, by age group

\begin{tabular}{lccc}
\hline Patient characteristics & $\begin{array}{c}\text { All } \\
\text { patients } \\
(\boldsymbol{n}=\mathbf{1 , 9 0 3 )}\end{array}$ & $\begin{array}{c}\text { Age } \geq \\
\mathbf{6 5} \text { years } \\
(\boldsymbol{n}=\mathbf{9 7 5})\end{array}$ & $\begin{array}{c}\text { Age }< \\
\mathbf{6 5} \text { years } \\
(\boldsymbol{n}=\mathbf{9 2 8})\end{array}$ \\
\hline Age, median (IQR), years & $65(50-77)$ & $77(70-82)$ & $50(36-58)$ \\
Female sex (\%) & $773(40)$ & $431(44)$ & $342(37)$ \\
Primary indication (\%) & & & \\
Medical encounters & $1,603(84)$ & $840(86)$ & $763(82)$ \\
$\quad$ Altered mental status & $938(49)$ & $395(41)$ & $543(59)$ \\
Respiratory failure & $515(27)$ & $358(37)$ & $157(17)$ \\
Airway obstruction & $116(6)$ & $77(8)$ & $39(4)$ \\
$\quad$ Other medical & $19(1)$ & $5(1)$ & $10(1)$ \\
Trauma encounters & $300(16)$ & $135(14)$ & $165(18)$ \\
Head trauma & $182(10)$ & $79(8)$ & $103(11)$ \\
Facial/neck trauma & $53(3)$ & $28(3)$ & $25(3)$ \\
Burn/inhalation & $42(2)$ & $19(2)$ & $23(2)$ \\
Other trauma & $23(1)$ & $9(1)$ & $14(2)$ \\
\hline
\end{tabular}

$I Q R$, interquartile range. Percentages may not equal 100 due to rounding.

blockade, were chosen in 682 patients (36\%) of the 1,903 intubations; rapid sequence intubation was the initial method chosen in $542(28 \%)$. Benzodiazepine was administered as the sedative in 630 patients (22\%), propofol in $447(23 \%)$ and ketamine in $66(3 \%)$. Of the 1,903 patients, 1,648 were successfully intubated within $\leq 2$ attempts (87\%). Ultimately, intubation was successful in 1,898 patients $(99.7 \%)$.

\section{Main results}

Overall, $2 \%$ of patients $(n=38)$ met the primary outcome of post-intubation hypotension (Table 3). The rate of hypotension was significantly higher in the elderly group compared with the younger group (3\% vs. $1 \%$; unadjusted OR, 2.7; 95\% CI 1.3-5.6; $P=0.005)$. After adjustment for potential confounders, advanced age was independently associated with post-intubation hypotension (adjusted OR, 2.6; 95\% CI, 1.3-5.6; $P=0.01$ ) (Table 4). The c-statistic for the model was 0.80 , and the Hosmer-Lemeshow test demonstrated a good fit $(P=0.55)$. In the sensitivity analyses, the adjusted association of increased rate of post-intubation hypotension with advanced age persisted with the use of different definitions for advanced age.

The overall adverse event rate was $13 \%(n=256$; Table 3). There was no significant difference in the overall adverse event rate between the elderly and younger group (14\% vs. 13\%; unadjusted OR, 1.0; $95 \% \mathrm{CI}$, $0.8-1.3 ; \quad P=0.91)$. This association remained nonsignificant after adjusting for predefined factors using a multivariable regression model (adjusted OR, 1.0; 95\% CI, 0.8-1.3; $P=0.97$; Table 4).

\section{Discussion}

In this large prospective multi-centre study of adult non-cardiac-arrest patients who underwent ED airway management, we found that patients aged 65 years or older had a significantly higher rate of post-intubation hypotension. Furthermore, after adjusting for a predefined set of confounding variables in a multivariable

Table 2 ED airway management characteristics in 1,903 study patients, by age group

\begin{tabular}{lccc}
\hline & $\begin{array}{c}\text { All } \\
\text { patients } \\
(\boldsymbol{n = 1 , 9 0 3 )}\end{array}$ & $\begin{array}{c}\text { Age } \geq \\
\mathbf{6 5} \text { years } \\
(\boldsymbol{n}=\mathbf{9 7 5})\end{array}$ & $\begin{array}{c}\text { Age }< \\
\mathbf{6 5} \text { years } \\
(\boldsymbol{n}=\mathbf{9 2 8}\end{array}$ \\
\hline Initial method (\%) & & & \\
$\quad$ Sedation without paralysis & $682(36)$ & $360(37)$ & $322(35)$ \\
Oral without medication & $546(29)$ & $298(31)$ & $248(27)$ \\
Rapid sequence intubation & $542(28)$ & $269(28)$ & $273(29)$ \\
Other* & $133(7)$ & $48(5)$ & $85(9)$ \\
Initial device (\%) & & & \\
$\quad$ Direct laryngoscope & $1,810(95)$ & $933(96)$ & $877(95)$ \\
Video laryngoscope & $44(2)$ & $17(2)$ & $27(3)$ \\
Othert & $49(3)$ & $25(3)$ & $24(2)$
\end{tabular}

Sedative (\%)

\begin{tabular}{lccc} 
No sedatives & $724(38)$ & $372(38)$ & $352(38)$ \\
Benzodiazepine & $630(22)$ & $343(35)$ & $287(31)$ \\
Propofol & $447(23)$ & $205(21)$ & $242(26)$ \\
Ketamine & $66(3)$ & $42(4)$ & $24(3)$ \\
Otherł & $36(2)$ & $13(1)$ & $23(2)$ \\
Paralytic (\%) & & & \\
No paralytics & $1,291(68)$ & $689(71)$ & $602(65)$ \\
Rocuronium & $402(21)$ & $177(18)$ & $225(24)$ \\
Vecuronium & $150(8)$ & $75(8)$ & $75(8)$ \\
Succinylcholine & $60(3)$ & $34(3)$ & $26(3)$ \\
Specialty of first intubator (\%) & & & \\
Transitional year resident§ & $703(37)$ & $384(39)$ & $319(34)$ \\
Emergency medicine resident & $648(34)$ & $298(31)$ & $350(39)$ \\
Emergency physician & $348(18)$ & $180(18)$ & $168(18)$ \\
Other specialties & $202(11)$ & $113(12)$ & $89(10)$ \\
Number of intubation attempts, & $1(1-2)$ & $1(1-2)$ & $1(1-2)$ \\
median (IQR) & & & \\
$>$ 3 intubation attempts (\%) & $255(13)$ & $128(13)$ & $127(14)$ \\
Ultimate intubation success (\%) & $5(<1)$ & $3(<1)$ & $2(<1)$ \\
\hline
\end{tabular}

IQR, interquartile range.

*Defined as oral intubation using paralytics without sedatives, transnasal intubation or cricothyrotomy.

tDefined as oral intubation using a bougie, lighted stylet, laryngeal mask airway and fibroscopy, transnasal intubation or cricothyrotomy.

$\neq$ Defined as administration of thiopental, haloperidol or combination with any of the included sedative categories.

$\S$ Defined as post-graduate years 1 and 2 .

IDefined as surgery, anaesthesia or paediatrics. 
Table 3 Unadjusted adverse event rates by age group, by age group

\begin{tabular}{|c|c|c|c|c|c|}
\hline Adverse events* & $\begin{array}{l}\text { All patients } \\
(n=1,903)\end{array}$ & $\begin{array}{c}\text { Age } \geq 65 \text { years } \\
\qquad(n=975)\end{array}$ & $\begin{array}{l}\text { Age }<65 \text { years } \\
\qquad(n=928)\end{array}$ & $\begin{array}{c}\text { Unadjusted OR } \\
\text { for age } \geq 65 \text { years } \\
(95 \% \mathrm{Cl})\end{array}$ & $P$ Value \\
\hline Hypotension & $38(2)$ & $28(3)$ & $10(1)$ & $2.7(1.3-5.6)$ & 0.005 \\
\hline \multicolumn{6}{|l|}{ Other adverse events } \\
\hline Dysrhythmia & $2(<1)$ & 0 & $2(<1)$ & $+\mathrm{N} / \mathrm{A}$ & $+N / A$ \\
\hline Cardiac arrest & $6(<1)$ & $3(<1)$ & $3(<1)$ & $1.0(0.2-4.7)$ & 0.95 \\
\hline Death & $6(<1)$ & $2(<1)$ & $4(<1)$ & $0.5(0.1-2.6)$ & 0.38 \\
\hline Oesophageal intubation with delayed recognition & $90(5)$ & $45(5)$ & $46(5)$ & $0.9(0.6-1.4)$ & 0.82 \\
\hline Dental/lip trauma & $68(4)$ & $29(3)$ & $39(4)$ & $0.7(0.4-1.1)$ & 0.15 \\
\hline Mainstem bronchus intubation & $32(2)$ & $22(2)$ & $10(1)$ & $2.1(1.0-4.5)$ & 0.05 \\
\hline Regurgitation & $35(2)$ & $10(1)$ & $25(3)$ & $0.4(0.2-0.8)$ & 0.007 \\
\hline Hypoxemia & $8(<1)$ & $4(<1)$ & $4(<1)$ & $1.0(0.2-3.8)$ & 0.94 \\
\hline Airway trauma & $5(<1)$ & $2(<1)$ & $3(<1)$ & $0.6(0.1-3.8)$ & 0.61 \\
\hline All groups combined & $256(13)$ & $132(14)$ & $124(13)$ & $1.0(0.8-1.3)$ & 0.91 \\
\hline
\end{tabular}

$C l$, confidence interval; $N / A$, not analysed.

*Patients may have more than one adverse event.

†The odds ratio for this variable was not calculated because there were too few events.

Table 4 Multiple logistic regression model with cardiovascular adverse event and any adverse event as the dependent variable

\begin{tabular}{|c|c|c|c|c|}
\hline \multirow[b]{2}{*}{ Variable } & \multicolumn{2}{|c|}{ Post-intubation hypotension } & \multicolumn{2}{|c|}{ Overall adverse event } \\
\hline & OR $(95 \% \mathrm{Cl})$ & $P$ Value & OR $(95 \% \mathrm{Cl})$ & $P$ Value \\
\hline \multicolumn{5}{|l|}{ Primary exposure } \\
\hline Age $\geq 65$ years (vs. $<65$ years) & $2.6(1.3-5.6)$ & 0.01 & $1.0(0.8-1.3)$ & 0.97 \\
\hline \multicolumn{5}{|l|}{ Age (categorical variable)* } \\
\hline Age $\geq 80$ years (vs. $<80$ years) & $2.4(1.2-4.8)$ & 0.01 & $0.98(0.7-1.4)$ & 0.92 \\
\hline Age, decile (ordinal variable: OR per each incremental decile)* & $1.3(1.1-1.7)$ & 0.01 & $0.98(0.9-1.1)$ & 0.66 \\
\hline \multicolumn{5}{|l|}{ Covariate } \\
\hline Female (vs. male) & $1.1(0.6-2.2)$ & 0.75 & $1.5(1.1-1.9)$ & 0.009 \\
\hline Primary indication & & 0.68 & & 0.88 \\
\hline Medical & $1.2(0.5-3.2)$ & & $1.0(0.7-1.5)$ & \\
\hline Trauma & 1 [reference] & & 1 [reference] & \\
\hline Sedative (\%) & & 0.001 & & 0.14 \\
\hline No sedatives & $0.1(0.01-1.0)$ & & $1.2(0.8-1.7)$ & \\
\hline Benzodiazepine & $3.6(1.3-10.0)$ & & $1.5(1.0-2.3)$ & \\
\hline Propofol & 1 [reference] & & 1 [reference] & \\
\hline Ketamine & $1.0(0.1-9.2)$ & & $0.9(0.4-2.2)$ & \\
\hline Othert & $5.9(1.0-31.8)$ & & $2.1(0.9-4.9)$ & \\
\hline Method & & 0.58 & & 0.73 \\
\hline RSI & $1.2(0.6-2.5)$ & & $1.1(0.7-1.6)$ & \\
\hline Non-RSI‡ & 1 [reference] & & 1 [reference] & \\
\hline Multiple attempts§ (vs. 2 or fewer attempts) & $(0.4-2.6)$ & 0.98 & $4.7(3.4-6.4)$ & $<0.001$ \\
\hline
\end{tabular}

$O R$, odds ratio; $C l$, confidence interval; $R S I$, rapid sequence intubation.

*Sensitivity analyses.

tDefined as administration of thiopental, haloperidol or combination with any of the included sedative categories.

‡Defined as oral intubation without medication, with sedatives only, or with paralytics only, transnasal intubation and cricothyrotomy.

$\S$ Defined as 3 or more intubation attempts. 
analysis, we found that advanced age was an independent predictor of post-intubation hypotension.

Our findings are difficult to compare with others' results because this topic is not well addressed in previous research. Reich et al. performed a retrospective analysis involving 4,096 anaesthesia records from a single centre [24]. The author found that age 50 years or older was independently associated with the occurrence of hypotension after general anaesthesia. A previous smaller study from Hong Kong involving 160 ED patients found that midazolam caused more hypotension than etomidate, particularly in elderly patients [13]. Although this study assessed the intubation-related adverse events in the ED setting, the study hypothesis was not explicitly stated and the association between age and adverse events was not significant likely because of type II errors. To our knowledge, this is the first emergency medicine study providing evidence that the incidence of postintubation hypotension accelerates with advanced age.

Aging affects cardiac function in many ways. Stiffening of large arteries increases after-load, while myocardial stiffening impairs early diastolic filling $[25,26]$. Conduction abnormalities and bradyarrhythmias are more prevalent in the elderly, potentially contributing to cardiac arrest [27]. Additionally, chronic illness and disability are common in the elderly. Exacerbations of chronic cardiac diseases often exhaust the patient's limited cardiovascular reserve, leading to hypotension, dysrhythmia and cardiac arrest. Diminished overall cardiovascular reserve in elderly patient results in heightened sensitivity to the negative inotropy and vasodilatory effects of induction agents and other vasoactive drugs. Furthermore, a drop in diastolic pressure and coronary perfusion pressure can have deleterious effects in patients with preexisting coronary artery disease. In elderly patients, the goals of airway management are not only to provide appropriate intubation condition, but also to preserve myocardial and haemodynamic function, control for the effects of pre-existing disease and avoid adverse events such as hypotension or dysrhythmia [28].

Out data establish an association between advanced age and post-intubation hypotension in the ED. In contrast, we cannot evaluate the effect of intubation-related hypotension in elderly patients on long-term mortality as this registry was not designed to measure patient outcomes after ED dispositions. One may surmise that a transient adverse event in the ED setting is a benign or self-limited consequence of airway management [29]. Indeed, hypotension has been described as a physiologic response to intubation caused by multiple mechanisms, such as induction-associated sympatholysis and the effects of positive pressure ventilation [30]. However, intubationassociated hypotension is associated with long-term morbidity and mortality across differing patient populations and clinical settings $[24,30-33]$. In the setting of exacerbations of chronic cardiopulmonary diseases, frank hypotension induced by intubation may act as a secondary insult that incites or advances hypoperfusion and directly contributes to organ dysfunction in critically ill elderly patients who undergo emergency airway management. Thus, advanced age may represent a high-risk marker of cardiovascular outcomes that warrants an early and organised haemodynamic resuscitation approach.

Our findings have important implications for the practice and training of emergency physicians and provide an opportunity to rethink the approach to airway management in critically ill elderly patients for the promotion of patient safety. Safe and effective emergency airway management, especially for patients with tenuous haemodynamics or poor cardiovascular reserve, requires specialty care provided by residency trained emergency physicians, anaesthesiologists and critical care physicians who can safely combine volume resuscitation, judicious use of vasoconstrictors and appropriate doses of induction agents. Improvements in training may lead to higher success rates as well as lower adverse event rates. Nevertheless, our data do not provide specific evidence that an approach with specific medications or methods would provide better clinical outcomes or fewer cardiovascular adverse events in elderly patients. We hope that this ongoing registry will compile a larger data set to allow for testing of this clinical question.

\section{Limitations}

We acknowledge important limitations in this study. First, passive surveillance introduces the potential of reporting bias. Therefore, underreporting of the number of adverse events is possible even though a previously applied reporting system with structured data forms with uniformed definitions and a high capture rate limit this possibility. Furthermore, assuming that underestimation of the number of adverse events occurred evenly in the both groups, this non-differential misclassification would not have biased our inference. Second, our patients were monitored via noninvasive or invasive blood pressure assessment, and post-intubation haemodynamic changes may have gone undetected because of the intermittent nature of this monitoring. In addition, mean arterial pressure, which might be more relevant to septic patients, was not measured in this study. Another important limitation is that, as with any observational study, the association between advanced age and the increased rate of post-intubation hypotension does not prove causality and might be confounded by unmeasured factors. For instance, potential confounding variables may include underlying cardiovascular risk. We did not have this information. However, we did adjust for primary indication to help account for this possible confounder. 
Furthermore, we attempted to minimise other confounding factors by adjusting for sex, indication, method of intubation, sedatives and multiple intubation attempts. Finally, we recognise that no patients received etomidate as it has not been approved by the Japanese Ministry of Health, Labour and Welfare. Therefore, these results may not be generalisable to those patients intubated using etomidate. However, our observation is valuable in resource-limited environments such as developing countries where etomidate is unavailable.

\section{Conclusions}

In this large multi-centre cohort of adult ED patients who underwent emergent airway management, we demonstrated that age 65 years or older was an independent predictor of post-intubation hypotension. These data provide implications for the education and practice of ED airway management that may lead to better clinical outcomes and improved patient safety.

\section{Abbreviations}

Cl: Confidence interval; ED: Emergency department; IQR: Interquartile range; JEAN: Japanese emergency airway network; OR: Odds ratio; SD: Standard deviation.

\section{Competing interests}

The authors declare that they have no competing interests.

\section{Authors' contributions}

$\mathrm{KH}$ and DFMB conceived the study. $\mathrm{KH}$ obtained research funding. $\mathrm{KH}, \mathrm{YH}$, $H W, T C$ and $C A B$ supervised the conduct of the trial and data collection. $\mathrm{YH}, \mathrm{HW}$ and TC managed the data, including quality control. $\mathrm{YH}$ and $\mathrm{HW}$ provided statistical advice on study design and analysed the data; $\mathrm{KH}$ chaired the data oversight committee. $\mathrm{KH}$ and TI drafted the manuscript, and all authors contributed substantially to its revision. $\mathrm{KH}$ take responsibility for the paper as a whole. All authors read and approved the final manuscript.

\section{Acknowledgments}

The authors acknowledge the following research personnel at the study hospitals for their assistance with this project: Fukui University Hospital (Hiroshi Morita, MD), Fukui Prefectural Hospital (Hideya Nagai, MD), Japanese Red Cross Medical Center of Wakayama (Hiroshi Okamoto, MD), Kameda Medical Center (Kenzo Tanaka, MD), National Center for Global Health and Medicine (Shunichiro Nakao, MD), Nagoya Ekisaikai Hospital (Yukari Goto, MD), Nigata City General Hospital (Nobuhiro Sato, MD, MPH), Obama Municipal Hospital (Yukinori Kato, MD), Okinawa Chubu Prefectural Hospital (Masashi Okubo, MD), Osaka Saiseikai Senri Hospital (Kazuaki Shigemitsu), Shonan Kamakura General Hospital (Hisashi Ofuchi, MD), Kurashiki Central Hospital (Hiroshi Okamoto, MD) and St. Marianna University School of Medicine Hospital (Yasuaki Koyama, MD). Finally, we are grateful to our many emergency physicians for their perseverance in pursuing new knowledge about this vital resuscitative procedure.

\section{Funding}

This study was supported by a grant from St. Luke's Life Science Institute and a grant from Massachusetts General Hospital and Brigham and Women's Hospital. The study sponsors have no involvement in the study design, in the collection, analysis and interpretation of data; in the writing of the manuscript; and in the decision to submit the manuscript for publication.

\section{Author details}

'Departments of Emergency Medicine, Massachusetts General Hospital, 326 Cambridge Street, Suite 410, Boston, MA 02114, USA. 'Department of Pediatric Emergency and Critical Care Medicine, Tokyo Metropolitan Children's Medical Center, Fuchu, Japan. ${ }^{3}$ Department of Emergency
Medicine, Shonan Kamakura General Hospital, Kamakura, Japan. ${ }^{4}$ Department of Emergency Medicine, Obama Municipal Hospital, Obama, Japan. ${ }^{5}$ Department of Public Health and Preventive Medicine, Oregon Health and Science University, Portland, USA. ${ }^{6}$ Departments of Emergency Medicine, Brigham and Women's Hospital, Boston, USA. 'Departments of Emergency Medicine, Massachusetts General Hospital, Boston, USA.

Received: 7 January 2013 Accepted: 28 March 2013 Published: 24 April 2013

\section{References}

1. Werner CA: The older population: 2010. In., Novemver 2011 edn. US Census Bureau: Washington, DC: 2011.

2. 2012 National population projections. US Census Bureau: http://www. census.gov/population/projections/data/national/2012/summarytables.html. Accessed April 22, 2013.

3. World Population Prospects: The 2010 revision, highlights and advanced tables, United Nations Department of Economic and Social Affairs/ Population Division; 2010. http://esa.un.org/unpd/wpp/index.htm. Accessed April 22, 2013.

4. Roberts DC, McKay MP, Shaffer A: Increasing rates of emergency department visits for elderly patients in the United States, 1993 to 2003. Ann Emerg Med 2008, 51(6):769-774.

5. Sevransky JE, Haponik EF: Respiratory failure in elderly patients. Clin Geriatr Med 2003, 19(1):205-224.

6. Jones $A E$, Yiannibas $V$, Johnson $C$, Kline JA: Emergency department hypotension predicts sudden unexpected in-hospital mortality: a prospective cohort study. Chest 2006, 130(4):941-946.

7. Jones $A E$, Aborn $L S$, Kline JA: Severity of emergency department hypotension predicts adverse hospital outcome. Shock 2004, 22(5):410-414

8. Marchick MR, Kline JA, Jones AE: The significance of non-sustained hypotension in emergency department patients with sepsis. Intensive Care Med 2009, 35(7):1261-1264.

9. Cressey DM, Claydon P, Bhaskaran NC, Reilly CS: Effect of midazolam pretreatment on induction dose requirements of propofol in combination with fentanyl in younger and older adults. Anaesthesia 2001, 56(2):108-113

10. Jones NA, Elliott S, Knight J: A comparison between midazolam coinduction and propofol predosing for the induction of anaesthesia in the elderly. Anaesthesia 2002, 57(7):649-653.

11. Martin G, Glass PS, Breslin DS, MacLeod DB, Sanderson IC, Lubarsky DA, Reves JG, Gan TJ: A study of anesthetic drug utilization in different age groups. J Clin Anesth 2003, 15(3):194-200.

12. Vuyk J: Pharmacodynamics in the elderly. Best Pract Res Clin Anaesthesiol 2003, 17(2):207-218

13. Choi YF, Wong TW, Lau CC: Midazolam is more likely to cause hypotension than etomidate in emergency department rapid sequence intubation. Emerg Med J 2004, 21(6):700-702.

14. Hasegawa K, Hagiwara Y, Chiba T, Watase H, Walls RM, Brown DF, Brown CA 3rd: Emergency airway management in Japan: Interim analysis of a multi-center prospective observational study. Resuscitation 2012 83(4):428-433.

15. Imamura T 3rd, Brown CA, Ofuchi H, Yamagami H, Branch J, Hagiwara Y, Brown DF, Hasegawa K, on behalf of the Japanese Emergency Medicine Research Alliance I: Emergency airway management in geriatric and younger patients: analysis of a multicenter prospective observational study. Am J Emerg Med 2013, 31(1):190-196.

16. Walls RM, Brown CA 3rd, Bair AE, Pallin DJ: Emergency airway management: a multi-center report of 8937 emergency department intubations. J Emerg Med 2011, 41(4):347-354.

17. Mort TC: Emergency tracheal intubation: complications associated with repeated laryngoscopic attempts. Anesth Analg 2004, 99(2):607-613. table of contents.

18. Nishisaki A, Ferry S, Colborn S, Defalco C, Dominguez T 3rd, Brown CA Helfaer MA, Berg RA, Walls RM, Nadkarni VM: Characterization of tracheal intubation process of care and safety outcomes in a tertiary pediatric intensive care unit. Pediatr Crit Care Med 2010, 13(1):e5-e10.

19. Hasegawa K, Shigemitsu K, Hagiwara Y, Chiba T, Watase H, Brown CA 3rd, Brown DF: Association between repeated intubation attempts and 
adverse events in emergency departments: an analysis of a multicenter prospective observational study. Ann Emerg Med 2012, 60(6):749-754. e2.

20. Dronen SC, Merigan KS, Hedges JR, et al: A comparison of blind nasotracheal and succinylcholine-assisted intubation in the poisoned patient. Ann Emerg Med 1987, 16:650-652.

21. Vissers $R$, Barton $E$, Sagarin $M$, et al: Success and complication rates of rapid-sequence vs. non-rapid sequence intubation in 1200 emergency intubations. Acad Emerg Med 1985, 1998(5):481-482.

22. Langeron O, Masso E, Huraux C, Guggiari M, Bianchi A, Coriat P, Riou B: Prediction of difficult mask ventilation. Anesthesiology 2000, 92(5):1229-1236.

23. Tayal VS, Riggs RW, Marx JA, Tomaszewski CA, Schneider RE: Rapidsequence intubation at an emergency medicine residency: success rate and adverse events during a two-year period. Acad Emerg Med 1999, 6(1):31-37.

24. Reich DL, Hossain S, Krol M, Baez B, Patel P, Bernstein A, Bodian CA: Predictors of hypotension after induction of general anesthesia. Anesth Analg 2005, 101(3):622-628. table of contents.

25. Fleg JL: Alterations in cardiovascular structure and function with advancing age. Am J Cardiol 1986, 57(5):33C-44C.

26. Priebe $\mathrm{HJ}$ : The aged cardiovascular risk patient. $\mathrm{Br} J$ Anaesth 2000, 85(5):763-778

27. Jin F, Chung F: Minimizing perioperative adverse events in the elderly. Br J Anaesth 2001, 87(4):608-624.

28. Edwards ND, Callaghan LC, White T, Reilly CS: Perioperative myocardial ischaemia in patients undergoing transurethral surgery: a pilot study comparing general with spinal anaesthesia. Br J Anaesth 1995, 74(4):368-372

29. Franklin C, Samuel J, Hu TC: Life-threatening hypotension associated with emergency intubation and the initiation of mechanical ventilation. Am J Emerg Med 1994, 12(4):425-428.

30. Heffner AC, Swords D, Kline JA, Jones AE: The frequency and significance of postintubation hypotension during emergency airway management. J Crit Care 2012, 27(4):417. e419-417 e413.

31. Schwartz DE, Matthay MA, Cohen NH: Death and other complications of emergency airway management in critically ill adults. A prospective investigation of 297 tracheal intubations. Anesthesiology 1995, 82(2):367-376

32. Jaber S, Amraoui J, Lefrant JY, Arich C, Cohendy R, Landreau L, Calvet Y, Capdevila X, Mahamat A, Eledjam Jj: Clinical practice and risk factors for immediate complications of endotracheal intubation in the intensive care unit: a prospective, multiple-center study. Crit Care Med 2006, 34(9):2355-2361.

33. Monk TG, Saini V, Weldon BC, Sigl JC: Anesthetic management and one-year mortality after noncardiac surgery. Anesth Analg 2005, 100(1):4-10.

doi:10.1186/1865-1380-6-12

Cite this article as: Hasegawa et al:: Increased incidence of hypotension in elderly patients who underwent emergency airway management: an analysis of a multi-centre prospective observational study. International Journal of Emergency Medicine 2013 6:12.

\section{Submit your manuscript to a SpringerOpen ${ }^{\circ}$ journal and benefit from:}

- Convenient online submission

- Rigorous peer review

- Immediate publication on acceptance

- Open access: articles freely available online

- High visibility within the field

- Retaining the copyright to your article

Submit your next manuscript at $\gg$ springeropen.com 